\title{
Perception and Management of Obesity Among Pakistani Doctors
}

Farooq Butt ${ }^{1}$, Ayesha Farooq Butt ${ }^{2}$, Fatima Alam ${ }^{2}$, Nabiha Aslam ${ }^{2}$, Hussain Abdul Moeed ${ }^{2}$, Furqan A. Butt ${ }^{3}$

1. Surgery, University of Health Sciences, Gujranwala, PAK 2. Internal Medicine, Combined Military Hospital Lahore Medical College and Institute of Dentistry, Lahore, PAK 3. Genetics, University of Eastern Finland, Kuopio, FIN

$\square$ Corresponding author: Ayesha Farooq Butt, aya.apa@gmail.com

\section{Abstract}

\section{Background}

The incidence of obesity has been on the rise worldwide. In Pakistan alone, one in four adults is overweight/obese and thus at risk of developing a number of comorbidities such as cardiovascular disease and diabetes. This research aimed to examine how doctors perceived and managed their obese patients.

\section{Methods}

A standardized questionnaire was filled by 100 doctors working in Pakistan, either by hand or online. The study was conducted from November 2017 to January 2018.

\section{Results}

It was found that only $8 \%$ of doctors had completed a training course on obesity. Doctors discussed the links between obesity and diabetes (88\%) most often whilst neglecting cancer (30\%) and dementia (17\%). Only 60\% of doctors calculated body mass index (BMI) for adult obese patients, with general practitioners (GPs) being the most confident in discussing their weight issues ( $\mathrm{p}=0.001$ ). In terms of childhood obesity, $54 \%$ of doctors were confident in putting in place a weight management program. Doctors who checked their weight more than four times a year were found to calculate the BMI of children and adult patients more often $(\mathrm{p}=0.000$ and $\mathrm{p}=0.044$ ). Comparably, doctors of normal weight were more confident in managing the complications of adult obesity $(\mathrm{p}=0.015)$.

\section{Conclusion}

Received 02/10/2019

Review began 02/22/2019 Review ended 02/27/2019 Published 02/28/2019

\section{(c) Copyright 2019}

Butt et al. This is an open access article distributed under the terms of the Creative Commons Attribution License CC-BY 3.0., which permits unrestricted use, distribution, and reproduction in any medium, provided the original author and source are credited.
Training courses regarding obesity should be provided to doctors not only to increase their knowledge but also to increase their confidence levels in managing such patients. Further research needs to be carried out in order to understand the patients' perception of obesity management.

Categories: Endocrinology/Diabetes/Metabolism, Epidemiology/Public Health, Family/General Practice Keywords: health knowledge, attitudes, practice, obesity, physicians

\section{Introduction}

The incidence of obesity has increased drastically worldwide, being labeled a global pandemic 
in recent years [1], with Pakistan ranked ninth out of 188 countries [2]. According to the World Health Organization (WHO), the incidence of obesity has tripled worldwide since 1975 [3], with the number of overweight adults in 2016 reaching 1.9 billion [3]. In terms of children, the statistics are also worrisome; 41 million children under the age of five were classified as overweight in 2016 [3], with levels having increased drastically in recent decades [4].

By definition, obesity is classified according to body mass index (BMI), with levels greater than 30 being obese [5]. The effects of obesity on the body are multiple, and there is welldocumented evidence linking it to a number of comorbidities such as cardiovascular disease (CVD) [6], diabetes [7], surgical risk [8], sleep apnea [9], cancer [7], and dementia [10].

It is widely known that developing countries are facing a "double burden" of disease, struggling with problems due to both under- and over-nutrition [11]. Historically, Pakistan (as well as other third-world counterparts) has been associated with undernourishment, but due to recent changes in trends such as urbanization and the attainment of sedentary lifestyles [12], it has been found that one in four adults are now classified as overweight/obese [13]. Thus, it has become imperative to understand the impact of overnutrition and other non-communicable diseases (NCDs) not only on the population but also on healthcare.

Although there is much evidence regarding the prevalence and effects of obesity, there has been little work done on the perception of this disease by healthcare workers. This is a necessary element in tackling obesity, as the disease requires a multidisciplinary approach, with the knowledge and know-how of all stakeholders playing an important role. Although the American Medical Association (AMA) classified obesity as a disease in 2013, it has been found that doctors continue to treat it as a risk factor [14]. It would, therefore, be interesting to understand how doctors in Pakistan perceive obesity, which is an aspect of healthcare currently being ignored.

As a result, this research was aimed at local doctors, with the dual purpose of assessing their knowledge of obesity as well as their confidence levels in managing such patients.

\section{Materials And Methods}

This cross-sectional study was conducted from November 2017 to January 2018. A total of 100 doctors took part in the research. Data were collected from various tertiary hospitals, such as CMH Lahore, Medcare International Hospital, Gujranwala, and Bahawal Victoria Hospital, Bahawalpur. A convenience sampling technique was applied to doctors working in tertiary care outpatient departments (OPDs), whose forms were filled anonymously in accordance with ethical guidelines. Online questionnaires were randomly distributed via Google forms to additional cities throughout the country, including Islamabad, as well as more desolate rural areas of Punjab. The questionnaire has been presented in the Appendix.

The inclusion criteria included a minimum of five years MBBS and completion of a house job. Instructions were provided on online forms, instructing that doctors must complete these criteria and be practicing in Pakistan in order to be eligible to fill out the questionnaire.

The questionnaire was taken with consent from the University College Dublin Centre for Emergency Medicine and later modified to suit the Pakistani population. It consisted of various sections, with Section A comprising the practice's profile and demographics. Section B assessed the doctors' confidence in conducting health checks, calculating BMI, and discussing weight issues with obese patients, including common comorbidities such as cardiovascular disease and diabetes. 
Section C focused on childhood obesity, touching areas such as BMI calculations and barriers to managing such patients. Service accessibility was assessed in Section D while doctors were asked to classify their own weight in Section E.

Confidence levels were assessed on a scale of $1-4$, with 1 being not confident and 4 being very confident. Scales 1 and 2 were later cumulated as "not confident," with 3 and 4 considered "confident." A similar formula was used for frequencies of calculation (e.g., BMI) with 1 and 2 considered "not regularly" while 3 and 4 considered "regularly."

The cumulated data was entered into SPSS version 21 (IBM Corp., Armonk, NY, US) where a descriptive statistical analysis was performed. Chi-squared analysis was performed in order to assess the association between health-conscious doctors and their knowledge and attitudes concerning the disease. $\mathrm{p}<0.05$ was considered significant.

\section{Results}

Out of the 100 doctors taking part in the survey, $57 \%$ were male and $43 \%$ were female. The majority of them worked in cities (81\%), with three or more doctors in their respective department (58\%). More than half $(54 \%)$ were $\leqslant 40$ years old while the majority of specialties belonged to medicine (63\%). Only $8 \%$ of participants had completed training/courses in obesity. Further details can be assessed from Table 1. 


\section{Cureus}

\section{CHARACTERISTIC}

Practice location

Total number of doctors

Gender

Age group

Specialty

Socioeconomic status of patients

Volume of pediatric cases

Completion of courses/training in obesity
City

Suburban

Town

Rural

1

2

$\geq 3$

Male

Female

$\leq 30$

$31-40$

$41-50$

$51-60$

$>60$

Family Medicine

Internal Medicine

Surgery

Paediatrics

Upper

Middle

Lower

Small

Average

Large

Yes

No

$4 \quad 4$

33

$11 \quad 11$

$30 \quad 30$

$12 \quad 12$

$57 \quad 58$

$56 \quad 57$

$43 \quad 43$

$38 \quad 38$

$16 \quad 16$

$16 \quad 16$

$25 \quad 25$

$4 \quad 4$

$32 \quad 32$

$31 \quad 31$

$20 \quad 20$

$17 \quad 17$

$13 \quad 13$

$47 \quad 47$

$39 \quad 39$

$48 \quad 48$

$38 \quad 38$

$13 \quad 13$

$8 \quad 8$

$92 \quad 92$

\section{TABLE 1: Practice Profile and Demographics}




\section{Cureus}

A large proportion (66\%) of doctors reported confidence in conducting health checks on obese patients, with $87 \%$ being confident of discussing weight issues with an overweight/obese adult. As seen in Figure 1, doctors frequently discussed the links between obesity and diabetes (88\%), CVD (83\%), and surgical risk (64\%) but did not, however, discuss sleep apnea (44\%), cancer (30\%), and dementia (17\%). Although 60\% of doctors calculated BMI for an adult obese patient, only $33 \%$ calculated it for a patient of normal weight. In contrast to this, $37 \%$ of doctors calculated BMI/weighed adolescents/children during a consultation. The single largest barrier to calculating BMI was noted to be lack of time (54\%) while the least important barrier was the cost to the practice (17\%).

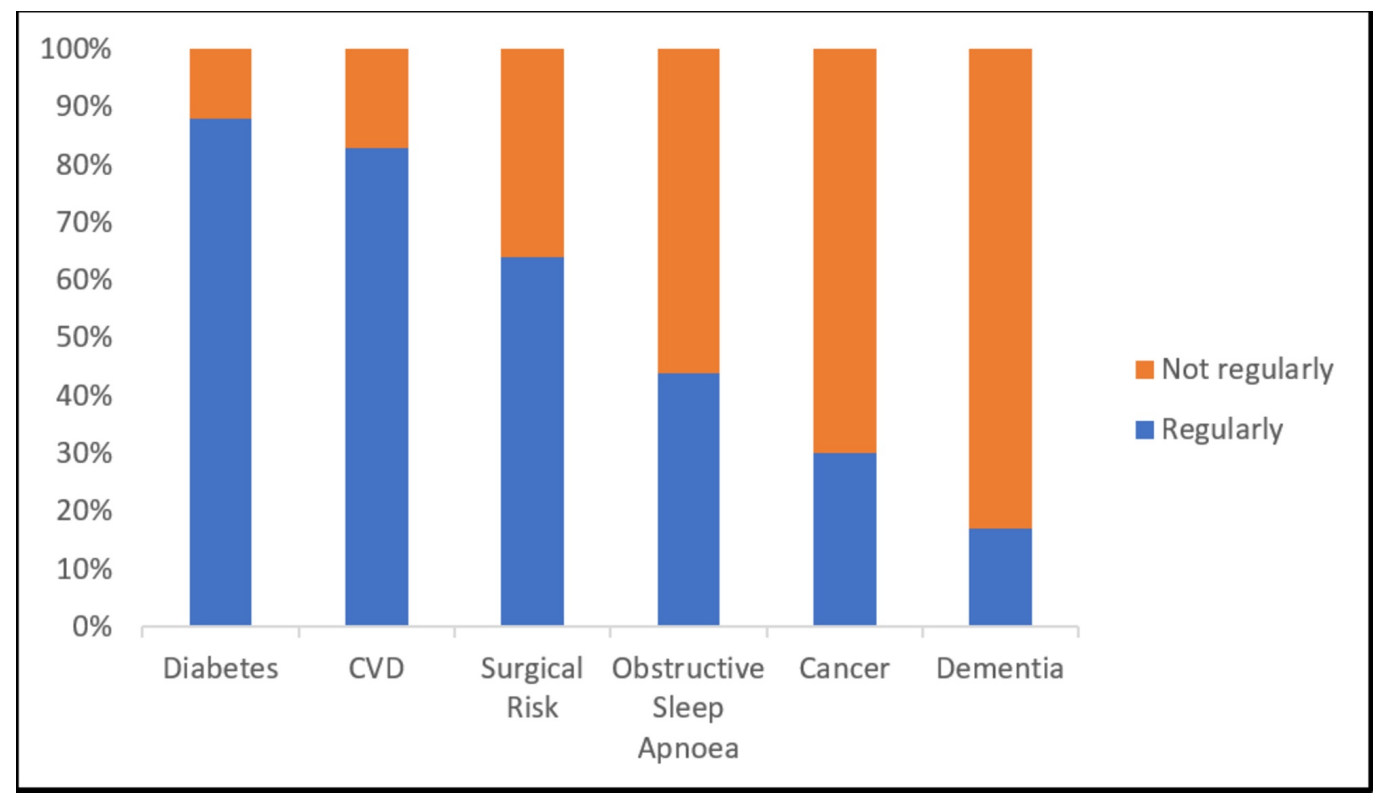

FIGURE 1: Frequency by Which Doctors Discuss the Links Between Obesity and Known Comorbidities

The four most important factors in addressing adult obesity were noted to be the patient (95\%), the dietitian (93\%), the general practitioner (88\%), and the patient's family (88\%). It was found that $68 \%$ of doctors said they were confident of managing the complications of adult obesity, and $67 \%$ remained confident while putting in place a weight management program. However, assuming that such a plan was to be put into place, only $34 \%$ of doctors were confident that their patients would comply.

When considering childhood obesity, more than half (55\%) of doctors raised the issue of a child's weight in consultation, with 54\% claiming confidence in putting in place a weight management program. Additionally, 56\% recommended follow-up, with only $31 \%$ confident that families would return. The noteworthy barriers to addressing childhood obesity were a lack of resources (82\%), socioeconomic factors affecting the ability of families to make a change (78\%), parents being unreceptive to advice (74\%), and lack of time (54\%).

When asked to evaluate the accessibility of various services for community members, physiotherapists were found to be the most accessible (52\%), followed by psychologists (37\%), dietitians (36\%), and public health nurses (27\%). Specialized weight services were found to be the least accessible (23\%).

Doctors were then asked to classify their own weight, where it was found that $55 \%$ claimed to be 


\section{Cureus}

of normal weight and $43 \%$ classified themselves as either overweight or obese. When asked how often they calculated their own weight, $63 \%$ of doctors calculated their weight less than four times a year while $37 \%$ checked their weight more than four times a year.

While medical specialists calculated BMI for obese patients more often than GPs ( $\mathrm{p}=0.002)$, GPs were the most confident in discussing weight issues with adult overweight/obese patients $(\mathrm{p}=0.001)$.

Doctors who were more confident in conducting health checks and who regularly calculated BMI for adult obese patients were more confident in putting in place weight management programs ( $p=0.048$ and $p=0.004$, respectively). Similarly, doctors who calculated BMI for obese patients did so more often for patients of normal weight $(\mathrm{p}=0.000)$. Moreover, it was found that these doctors considered dietitians to be more important than other factors in tackling obesity $(\mathrm{p}=0.010)$.

Doctors who checked their own weight more often ( $\geqslant 4$ times/year) were found to calculate the BMI of normal adult patients and children/adolescents more often ( $\mathrm{p}=0.044$ and $\mathrm{p}=0.000$, respectively). They additionally felt that dietitians were more important in addressing adult obesity as opposed to other entities ( $\mathrm{p}=0.039)$ when compared to doctors who checked their weight less often (<4 times/year).

It was found that not only did doctors of normal weight calculate the BMI of adult obese patients more often $(\mathrm{p}=0.003$ ), they were also more confident in managing the complications of adult obesity ( $\mathrm{p}=0.015$ ) and more frequently raised the issue of a child's weight when in consultation for an unrelated problem $(\mathrm{p}=0.001)$. Moreover, they were more confident than overweight/obese doctors when it came to their counseling skills regarding childhood obesity $(\mathrm{p}=0.034)$. Table 2 shows these associations.

\section{CATEGORY}

Doctors who checked their weight $\geq 4$ times/year

Calculated BMI of patients of normal weight more often

Calculated BMI of children more often

0.000

Felt dietitians were more important than other services in tackling obesity

Calculated BMI of obese patients more often

Were more confident in managing the complications of adult obesity

Were more confident in their counseling skills regarding childhood obesity

TABLE 2: Positive Associations Found in Doctors Who Weighed Themselves $\geq 4$ Times/Year and Those with Normal Weight 


\section{Discussion}

\section{Summary of findings}

The purpose of this study was to understand the perception of Pakistani doctors of obesity and their management of the disease. It was found that while only $8 \%$ of the subjects had completed a training course in obesity, $66 \%$ were confident in conducting health checks on an obese patient. General practitioners were the most confident in managing an obese patient.

Doctors were noted to regularly discuss with obese patients the link between obesity and diabetes and cardiovascular disease and surgical risk, however, they did not regularly discuss obstructive sleep apnoea, cancer, and dementia. While dietitians were noted to be the second most important factor in addressing adult obesity, only $36 \%$ of doctors reported the accessibility of this service for their patients.

Doctors confident in conducting health checks and more regular in calculating BMI for obese patients were found to not only be more confident in advising weight management programs but also understood the importance of dietitians in tackling obesity. Additionally, doctors regular in calculating BMI for obese patients also did so for their normal counterparts.

Weight-conscious doctors were found to be more regular in calculating adult and child/adolescent BMI. Furthermore, doctors of normal weight were more confident in managing the complications of adult obesity as well as in their counseling skills regarding childhood obesity.

\section{Strengths and limitations}

To our knowledge, this is the first research of its kind to be carried out in Pakistan. It is hoped that this research will be able to fill the gap that exists in understanding the impact and burden of obesity on the country's healthcare system. As little research is present with regards to doctors' perspectives on obesity management, it is hoped that more focus will be paid to this neglected area. Obesity requires a multidisciplinary team; therefore, it is necessary to understand its impact not only on the patient but also on those managing the disease.

A standardized questionnaire was used in this research, allowing the possibility of carrying out similar studies in different regions of the country/different countries. Additionally, the same research could also be carried out in the same setup after a number of years in order to assess if knowledge and attitudes about obesity have changed. The fact that an online form was also used was advantageous, as it allowed the study to be carried out in rural areas, which were difficult to access otherwise, allowing a more comprehensive approach to targeting the country's healthcare system.

The major limitation of this research was the fact that all aspects of healthcare were not considered when selecting subjects. Healthcare in Pakistan consists of multiple tiers, beginning at the primary level and extending to tertiary healthcare. Future research could be carried out focusing on primary healthcare in particular, as this serves as the first contact patients have with the country's healthcare system.

The sample size and demographics of this research also posed as limitations. Further studies should be carried out with more participants, not only in number but also in the proportion of those working in rural areas. Along with widening the scope of this research, it would also allow for a more comprehensive assessment of doctors' knowledge and attitudes regarding obesity.

As English is not the first language of the Pakistani population, some questions proved difficult 
to interpret, particularly those requiring doctors to grade statements beginning with "I lack confidence..." as "not valid" or "valid." A similar case was seen with statements carrying double-negative annotations, which could have been avoided had a pilot study been carried out.

It was not possible to assess the level of honesty shown by participants in research while filling out the questionnaire. Inclusion criteria could not be strictly adhered to in the case of online forms. Some questionnaires were inappropriately and incompletely filled.

\section{Comparison with existing literature}

While our study reported doctors having little training in obesity, research conducted in the UK showed similar results in terms of nursing staff [15]. Another interesting comparison can be drawn from doctors' confidence levels in conducting health checks on obese patients: while $66 \%$ of doctors from our study claimed confidence, only $44 \%$ of residents felt qualified to treat such patients in the US [16]. Doctors elsewhere also carried negative opinions about their roles in managing obesity, including their knowledge and confidence levels [17-18].

The presence of dietitians, psychologists, and physiotherapists was universally stressed [18]. Lack of time was cited as a major barrier to managing obese patients [18-20]. Interestingly, this was also found to be a significant barrier for caretakers in addressing their child's obesity [21].

Our research found that health-conscious behavior is shown by doctors of normal weight and who calculate BMI more regularly for obese patients. It is interesting to note that a similar study found that doctors with normal BMI began discussing weight-loss options at lower patient BMI levels [22]. Thus, it would be noteworthy to draw a comparison/further examine how-weight conscious doctors manage their obese patients.

Doctors considered obese have been reported to be less confident in dealing with exercise counseling [23]. This reinforced our finding that doctors of normal weight were more confident in the management and counseling of adult and childhood obesity, respectively. Doctors were also found to lack confidence in the management of childhood obesity in particular [18]. Parent perception of childhood obesity was also a recurrent topic of discussion. While we found that parent receptiveness was a major barrier to addressing the issue, another study noted that parent motivation also hindered their progress in managing obese children [18].

Since obesity management not only includes the doctor but also dietitians, psychologists, physiotherapists, and nurses, it would be interesting to expand this research to include these stakeholders as well. This would not only provide additional information as to their degree of knowledge but allow for the comparison of attitudes regarding management. Additionally, it is imperative that access to these services be increased in both rural and urban areas for greater efficacy in tackling the disease.

\section{Implications for research/policy}

Further research could be carried out in terms of the patients' point of view regarding their existing knowledge of obesity, barriers to receiving effective healthcare, and treatment satisfaction. Since doctors are not confident in their patients returning for follow-up, it would be noteworthy to consider the barriers patients face in doing so. Additionally, researchers have found that doctors' BMI can also impact patient responses [17], which is another aspect of obesity management yet to be examined in our country.

It is suggested that training courses be provided to doctors regarding obesity since it has been seen that attending such programs can change their attitudes towards it [17]. Due to the fact 


\section{Cureus}

that higher confidence levels were seen in doctors who calculated weight more often for themselves and patients, it is recommended that this behavior be promoted at all levels of healthcare.

The disparity between the management of childhood and adult obesity must also be further examined. Confidence levels in management are notably decreased for childhood populations, which is alarming. The prevalence of childhood obesity, as well as its management and effect on healthcare, are areas of study requiring further research in Pakistan.

Studies could also be carried out in order to ascertain whether doctors regard obesity as a risk factor or a disease since this can also impact management [14]. Additionally, it would be interesting to compare this study with similar ones carried out in developed countries in order to examine differences in doctors' knowledge and attitudes.

\section{Conclusions}

Obesity is rapidly on the rise worldwide. However, current trends in obesity management have shown deficits in knowledge, confidence, and training. In order for obesity to be managed in a comprehensive fashion, essential amenities, such as dietitians, must be provided to communities to better supplement existing medical management. With an ever-increasing incidence rate, it has become imperative that doctors not only have knowledge but also the tools to tackle this pandemic.

\section{Appendices}

\section{Questionnaire}

\section{TERMINOLOGY

$\begin{array}{lllll}\text { Adult: } & \geq 18 \text { years } & \text { Underweight: } \mathrm{BMI}<18.5 \mathrm{kgs} / \mathrm{m}^{2} & \text { Overweight: } & \text { BMI 25-30kg } / \mathrm{m}^{2} \\ \text { Adolescent: } & 13-17 \text { years } & \text { Normal weight: BMl } 18.5-25 \mathrm{kgs} / \mathrm{m}^{2} & \text { Obese: } & \text { BMl>30kgs } / \mathrm{m}^{2}\end{array}$ \\ Child: $\quad 5-12$ years}

\section{A: $\quad$ PRACTICE PROFILE AND DEMOGRAPHICS}

A1 Which best describes your practice location?

A2 How many doctors, including yourself?

A3 Your gender?

A4 Your age group?

A5 Your specialty?

A6

What socioeconomic class do the majority of your patients belong to?

A7 How would you describe the volume of paediatric case handling in your practice?

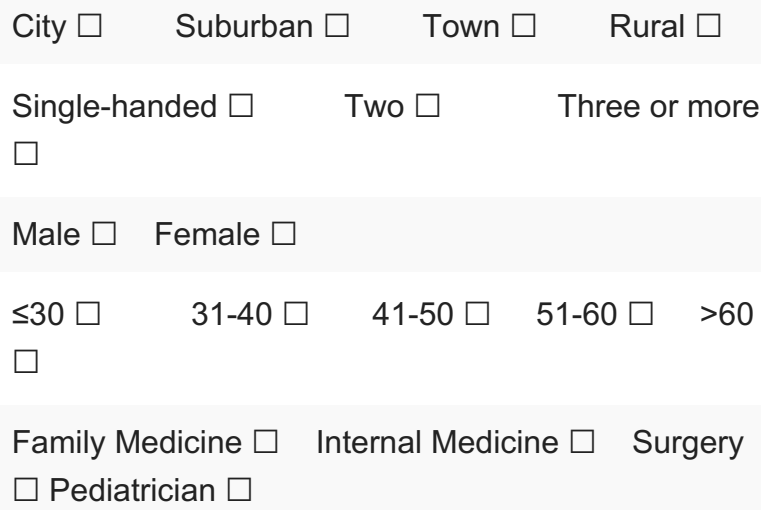




\section{Cureus}

A8 Have you completed any courses or training on obesity? $\quad$ Yes $\square \quad$ No $\square$

\section{B: ADULT PATIENTS WHO ARE OVERWEIGHT/OBESE}

B1 How confident are you in conducting health checks on overweight/obese adults?

B2 How confident are you in discussing weight issues with an overweight/obese adult when in consultation?



B3 How frequently do you discuss with adu
the following conditions and obesity?
A Obesity and cardiovascular disease
B Obesity and obstructive sleep apnoea
C Obesity and diabetes
D Obesity and cancer
E Obesity and dementia
F Obesity and surgical risk

\begin{tabular}{|c|c|c|c|}
\hline $1 \square$ & $2 \square$ & $3 \square$ & $4 \square$ \\
\hline $1 \square$ & $2 \square$ & $3 \square$ & $4 \square$ \\
\hline $1 \square$ & $2 \square$ & $3 \square$ & $4 \square$ \\
\hline $1 \square$ & $2 \square$ & $3 \square$ & $4 \square$ \\
\hline $1 \square$ & $2 \square$ & $3 \square$ & 4 \\
\hline $1 \square$ & $2 \square$ & $3 \square$ & 4 \\
\hline
\end{tabular}

\section{B4}

How often do you calculate Body Mass Index (BMI) for:

\begin{tabular}{|c|c|c|c|c|c|}
\hline $1=$ & VER & $4=V E$ & FREQUE & Y 1 & \\
\hline$\square$ & $2 \square$ & $3 \square$ & $4 \square 1 \square$ & $2 \square$ & \\
\hline$\square$ & $\square$ & & & & \\
\hline
\end{tabular}

How important are the following in deterring you from $1=$ NOT IMPORTANT 4 = VERY IMPORTANT calculating an adult patient's BMI? Lack of time Cost to the

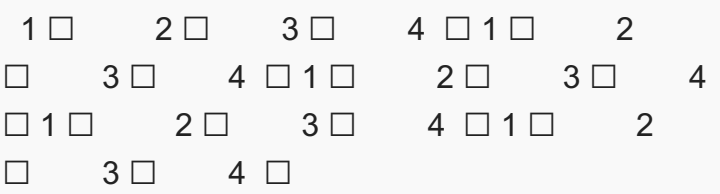

How confident are you in managing the complications of adult obesity, e.g. sleep apnoea, diabetes?

$1=$ NOT CONFIDENT $4=$ VERY CONFIDENT presenting complaint Lack of support / resources to provide additional or ongoing care for patients

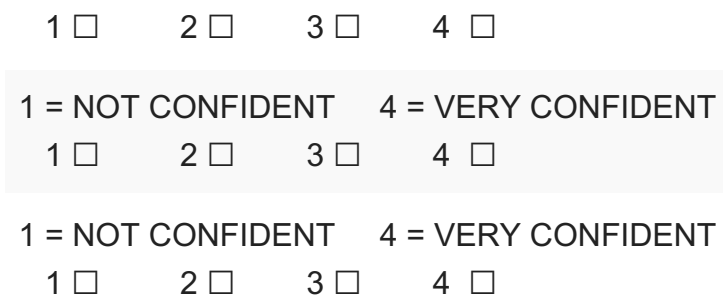

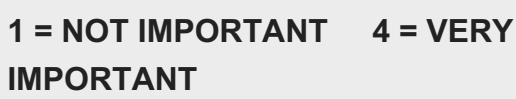
A The patient
B The patient's family
C General Practitioner
D Public Health Nurse
E Dietitian
F Physiotherapist

\begin{tabular}{|c|c|c|}
\hline $1 \square$ & $2 \square$ & $3 \square$ \\
\hline $1 \square$ & $2 \square$ & $3 \square$ \\
\hline$\square$ & $2 \square$ & $3 \square$ \\
\hline$\square$ & $2 \square$ & $3 \square$ \\
\hline$\square$ & $2 \square$ & $3 \square$ \\
\hline & $2 \square$ & $3 \square$ \\
\hline
\end{tabular}




\section{Cureus}

G Psychologist

H Specialised weight management services

I Commercial weight management services

$\mathrm{J}$ Better government regulation of the foods/drinks industry

K Responsible actions/marketing campaigns led from within the food/drinks industry

\begin{tabular}{|c|c|c|}
\hline $1 \square$ & $2 \square$ & $3 \square$ \\
\hline $1 \square$ & $2 \square$ & $3 \square$ \\
\hline $1 \square$ & $2 \square$ & $3 \square$ \\
\hline $1 \square$ & $2 \square$ & $3 \square$ \\
\hline $1 \square$ & $2 \square$ & $3 \square$ \\
\hline
\end{tabular}

\section{C: ADOLESCENTS AND CHILDREN WHO ARE OVERWEIGHT/OBESE}

1=never/not confident 4=always/very confident

C1 How often do you weigh and/or calculate a BMI Centile (BMI Z-score* ${ }^{*}{ }^{*}$ measure of relative weight adjusted for child's age and sex

$1 \square \quad 2 \square \quad 3$

$1 \square \quad 2 \square \quad 3$

$\square \quad 4 \quad \square$

C2

How confident are you discussing overweight/obesity with the parents of overweight/obese patients?

$1 \square \quad 2 \square \quad 3$

C3 How confident are you in putting in place a weight management plan to treat a child whom you

C4

Please rate the validity of these statements as potential barriers to addressing childhood obesity in your practice:

$1=$ not valid $\quad 4=$ highly valid

A Patients/parents are not receptive to healthy eating and physical activity advice

B I lack confidence in my own counselling skills regarding childhood obesity

C There is a lack of evidence of effective intervention

D There are time constraints

E There is a lack of support for me to undertake this work in general practice

F Socio-economic factors affect the ability of families to make a change

G There is a shortage of local/community-based resources

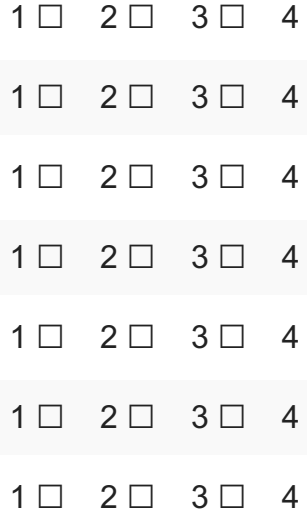

When an overweight/obese child presents with an unrelated problem, how frequently do you

$1 \square \quad 2 \square \quad 3 \square$ 4

$1 \square \quad 2 \square \quad 3 \square$ 4

$1 \square \quad 2 \square \quad 3 \square$ 4

$1 \square \quad 2 \square \quad 3 \square$ 4 


\section{Cureus}

C9

During the last two years, have parents ever become upset by you raising the issue of their

$1 \square \quad 2 \square \quad 3 \square$ child's overweight/obesity in consultation with them?

C10 If yes, how many times has this occurred?

\section{D: $\quad$ ACCESS TO SERVICES}

D1 Please indicate the level of access to each of these services in your practice for obese patients

$$
1=\text { not accessible } \quad 4 \text { = very accessible }
$$
A Dietitian
$1 \square \quad 2 \square \quad 3 \square \quad 4 \quad \square$
B Physiotherapist
$1 \square \quad 2 \square \quad 3 \square \quad 4 \quad \square$
C Psychologist
$1 \square \quad 2 \square \quad 3 \square \quad 4$
D Public Health Nursing
$1 \square \quad 2 \square \quad 3 \square \quad 4 \quad \square$
E Specialised weight management services
$1 \square \quad 2 \square \quad 3 \square \quad 4 \quad \square$
D2
How often do you recommend commercial weight management programmes
E:

\section{OPTIONAL *}
E1 How often do you check your own weight or calculate your BMI?
Monthly:
E2 How would you classify your own bodyweight?
Underweight:
Obese:

\section{F: COMMENTS}

If there are additional aspects of care that you wish to highlight, any other observations or comments would be appreciated

\section{TABLE 3: Perception and Management of Obesity Among Pakistani Doctors}

BMI: body mass index

\section{Additional Information \\ Disclosures}

Human subjects: Consent was obtained by all participants in this study. Animal subjects: All authors have confirmed that this study did not involve animal subjects or tissue. Conflicts of interest: In compliance with the ICMJE uniform disclosure form, all authors declare the following: Payment/services info: All authors have declared that no financial support was received from any organization for the submitted work. Financial relationships: All authors have declared that they have no financial relationships at present or within the previous three years with any organizations that might have an interest in the submitted work. Other relationships: All authors have declared that there are no other relationships or activities that 
could appear to have influenced the submitted work.

\section{Acknowledgements}

This research could not have been possible without the help of the Department of General Practice, UCD School of Medicine. The authors of this research are also grateful to the medical communities of Lahore, Bahawalpur, and Gujranwala for their unwavering support and encouragement.

\section{References}

1. Stevens GA, Singh GM, Lu Y, et al.: National, regional, and global trends in adult overweight and obesity prevalences. Popul Health Metr. 2012, 10:22. 10.1186/1478-7954-10-22

2. Prevalence and determinants of overweight and obesity among adults in Pakistan . (2015). Accessed: February 28, 2019: https://pide.org.pk/pdf/cphsp/PIDE-CPHSP-2.pdf.

3. WHO | Obesity and overweight. (2018). Accessed: February 28, 2019: https://www.who.int/news-room/fact-sheets/detail/obesity-and-overweight.

4. Güngör NK: Overweight and obesity in children and adolescents . J Clin Res Pediatr Endocrinol. 2014, 6:129-143. 10.4274/jcrpe.1471

5. WHO | Obesity. (2018). Accessed: February 28, 2019: https://www.who.int/topics/obesity/en/.

6. Bastien M, Poirier P, Lemieux I, Després J-P: Overview of epidemiology and contribution of obesity to cardiovascular disease. Prog Cardiovasc Dis. 2014, 56:369-381. 10.1016/j.pcad.2013.10.016

7. Gallagher EJ, LeRoith D: Obesity and diabetes: the increased risk of cancer and cancer-related mortality. Physiol Rev. 2015, 95:727-748.

8. Ri M, Aikou S, Seto Y: Obesity as a surgical risk factor. Ann Gastroenterol Surg. 2018, 2:13-21. 10.1002/ags3.12049

9. Gami AS, Caples SM, Somers VK: Obesity and obstructive sleep apnea. Endocrinol Metab Clin Am North. 2003, 4:869-894.

10. Kiliaan AJ, Arnoldussen IAC, Gustafson DR: Adipokines: a link between obesity and dementia?. Lancet Neurol. 2014, 13:913-923.

11. Kolčić I: Double burden of malnutrition: a silent driver of double burden of disease in lowand middle-income countries. J Glob Health. 2012, 2:1644S-1651S. 10.3945/ajcn.114.083857

12. Tanzil S, Jamali T: Obesity, an emerging epidemic in Pakistan-a review of evidence . J Ayub Med Coll Abbottabad. 2016, 28:597-600.

13. Jafar TH, Haaland BA, Rahman A, et al.: Non-communicable diseases and injuries in Pakistan: strategic priorities. Lancet. 2013, 381:2281-2290. 10.1016/S0140-6736(13)60646-7

14. Funk LM, Jolles SA, Voils CI: Obesity as a disease: has the AMA resolution had an impact on how physicians view obesity?. Surg Obes Relat Dis. 2016, 12:1431-1435.

15. Brown I, Stride C, Psarou A, Brewins L, Thompson J: Management of obesity in primary care: nurses? practices, beliefs and attitudes. J Adv Nurs. 2007, 59:329-341.

16. Block JP, DeSalvo KB, Fisher WP: Are physicians equipped to address the obesity epidemic? Knowledge and attitudes of internal medicine residents. Prev Med. 2003, 36:669-675.

17. Bocquier A, Verger P, Basdevant A, Andreotti G, Baretge J, Villani P, Paraponaris A: Overweight and obesity: knowledge, attitudes, and practices of general practitioners in France. Obes Res. 2012, 13:787-795. 10.1038/oby.2005.89

18. Rhee KE, Kessl S, Lindback S, Littman M, El-Kareh RE: Provider views on childhood obesity management in primary care settings: a mixed methods analysis. BMC Health Serv Res. 2018, 18:55.

19. Ferrante JM, Piasecki AK, Ohman-Strickland PA, Crabtree BF: Family physicians' practices and attitudes regarding care of extremely obese patients. Obesity. 2009, 17:1710-1716. 10.1038/oby.2009.62

20. Jansen S, Desbrow B, Ball L: Obesity management by general practitioners: the unavoidable necessity. Aust J Prim Health. 2015, 21:366-368. 10.1071/PY15018

21. Staiano AE, Marker AM, Comeaux J, Frelier JM, Hsia DS, Broyles ST: Family-based behavioral treatment for childhood obesity: caretaker-reported barriers and facilitators. Ochsner J. 2017, 17:83-92. 
Cureus

22. Bleich SN, Bennett WL, Gudzune KA, Cooper LA: Impact of physician BMI on obesity care and beliefs. Obesity (Silver Spring). 2012, 20:999-1005.

23. Stanford FC, Durkin MW, Stallworth JR, Powell CK, Poston MB, Blair SN: Factors that influence physicians' and medical students' confidence in counseling patients about physical activity. J Prev. 2014, 35:193-201. 